5. Демидов, А. Необходимо в сознании людей поменять отношение к культуре / А. Демидов, беседовала К. Воротынцева // Культура: [газета]. - 2021. - 8 июня. - URL: https://portalkultura.ru/articles/dostoyanie/333300-artem-demidov-voopiik-neobkhodimo-v-soznanii-lyudey-pomenyatotnoshenie-k-naslediyu/ (дата обращения: 24.08.2021).

Yury S. Putrik, Dr. of Historical Sciences Likhachov Russian Research Institute for Cultural and Natiral Heritage (Moscow, Russia) putrik@list.ru

Andrei P. Solovyov, Ph. D. in Pedagogics Likhachov Russian Research Institute for Cultural and Natiral Heritage (Moscow, Russia) andrey476_85@mail.ru

\title{
PERSPECTIVE LINES FOR EXPLOITATION OF CULTURAL HERITAGE SITES LOCATED WITHIN THE FRAMES OF PROTECTED ZONES IN THE RUSSIAN FEDERATION
}

\begin{abstract}
The paper briefly outlines legal framework of activities run by the modern Russian state for physical safekeeping cultural heritage sites, one of key form of which is making zones of protected natural landscape. The authors trace a graduately process of mainstreaming issues concerning preservation historical and cultural heritage sites and integration of these constructions into a structure of economic, social and cultural development of regions of the country. Researchers analyze a set of current problems in sphere of preservation and state protection of cultural heritage sites (such as lack of monetary funds and skilled workforce for repair and restoration, fulfilling research tasks, etc. Also, the article reviews ongoing programs for preservation cultural heritage sites located in the Russian capital, Moscow.
\end{abstract}

Keywords: cultural heritage, cultural heritage sites, охранные зоны, использование объектов культурного наследия, туризм.

УДК 069.51:391.2(=161.1)

DOI: 10.32340/2414-9101-2021-3-14-19

И. В. Куприянова, доктор исторических наук, доцент Алтайский государственный институт культуры (Барнаул, Россия) irinak-63@mail.ru

\section{ЭТНОГРАФИЧЕСКИЙ ПАМЯТНИК КАК ТРАНСЛЯТОР НЕМАТЕРИАЛЬНОГО НАСЛЕДИЯ}

\begin{abstract}
Аннотация. В статье предпринята попытка обосновать первичность нематериального наследия по отношению к материальному наследию, представленному в этнографических собраниях музеев на примере семантического анализа ключевых, с авторской точки зрения, памятников восточнославянской этнокультуры. Показана иерархическая связь между этими двумя компонентами культуры, в которой музейные памятники выступают в качестве овеществленных идей, отражающих традиционные представления о структуре мироздания, этические и эстетические взгляды и предпочтения. Обозначены возможности раскрытия особенностей народного мировоззрения через вещь.

Ключевые слова: русские, нематериальное наследие, материальное наследие, традиционная культура, этнокультура, мировоззрение, восточнославянские дохристианские верования, сакральность, традиционый текстиль.
\end{abstract}


Нематериальное наследие как составная часть народной традиции, выраженная в мировоззрении, фольклоре, системе ценностей, понятий об окружающем мире и связях с ним человека, представляет собой неосязаемые элементы культуры, не имеющие прямого материального выражения и видимой смысловой связи с предметами материального мира. Тем не менее, оно справедливо считается ценнейшим дополнением музейных фондов, которое имеет громадный потенциал для формирования образовательных и рекреационных программ и, что еще более важно, служит информативной нагрузкой к экспозициям и выставкам, помогающей раскрыть семантику музейного предмета.

Более того: в настоящее время ряд исследователей полагает, что материальные и нематериальные компоненты культуры следует воспринимать как равные по значению [1, с. 79]. Существует опыт презентации нематериального наследия как образа этнической культуры в музее [2, c. 55]. В частности, в музее-заповеднике «Кижи» в течение многих лет реализуется программа «Ожившая экспозиция», основная идея которой заключается в демонстрации сезонных занятий и народных ремесел в музее под открытым небом, в естественной среде крестьянских усадеб [3].

Вместе с тем, не менее важным, имеющим право на существование, представляется и обратное понимание иерархии материального и нематериального наследия, при котором материальный памятник является вторичным по отношению к нематериальному объекту, и служит выражением духовного наполнения религиозной или этнической традиции. Следовательно, в данной парадигме возможно раскрытие основополагающих смыслов той или иной культуры через вещь. В качестве инструментария этого раскрытия может быть использован семиотический анализ, преследующий цель интерпретации этнографического памятника как текста, в котором заложены особенности мировоззрения его создателей [4, с. 74].

В качестве уточнения можно отметить, что речь идет не о любой вещи, а предметах, в которых сосредоточены некие ключевые мировоззренческие смыслы; иными словами, предметы, представляющие не только и не столько утилитарную, сколько сакральную или сакрализованную (предметы утилитарного значения, адаптированные в качестве артефактов ритуала) часть материальной культуры этноса. В славянской культуре к вещам, обладающим подобными свойствами, обычно относят полотенце и пояс [5, с. 230]. Не оспаривая эту точку зрения, считаем правильным добавить к этим предметам такой предмет, как рубаха.

Фактором, объединяющим эти три предмета, является, прежде всего, то обстоятельство, что все они имеют отношение к одежде, не исключая и полотенце: как известно, в славянской древности существовал женский полотенечный головной убор - убрус. Важно, что полотенце здесь использовалось в его классическом варианте, поскольку знаковым, обрядовым его элементом являлись именно симметрично декорированные концы, выставлявшиеся напоказ. Таким образом, полотенце как элемент костюма бытовало в том же виде, что и в качестве предмета утилитарного назначения и ритуала.

Затем, все три предмета представляют традиционный текстиль и являются изделиями ручной работы. Хорошо известно, что текстиль - предметы из ткани ручного ткачества, шитья, кружевоплетения или орнаментации, захватывает большое пространство в предметном мире традиционной культуры. Такие вещи насыщали интерьер жилища, являлись предметами одежды, парадного постельного убранства и утвари; с помощью текстиля - занавесей, шторок, ковриков, скатертей, обозначалось функциональное разделение внутреннего пространства дома.

Стоит отметить при этом, что процесс создания полотна в славянской, как, впрочем, и во многих других культурах, имел не только утилитарное, но и сакральное значение. Структурным компонентом ткани является прядильное волокно, с которым связаны такие смыслы и понятия, как «нить судьбы», «нить жизни». Существовали женские божества, ответственные за этот процесс; у восточных славян это, прежде всего, Макошь (или Мокошь) - покровительница прядения и ткачества [6, с. 472]. В европейской мифологии богини, представляемые в образах небесных ткачих или прях - норны, мойры и др., являлись модификациями одного из самых древних архетипов - Великой Матери, культ которой возник на заре человечества, в период становления сознания; его зримым выражением являются, например, неолитические Венеры [7, с. 128]. К функ- 
циям этих божеств относилось не только покровительство женским рукоделиям, но также дарение и отнятие жизни, которое отождествлялось с пресечением посредством взмаха ножниц соответствующей нити или полотна, воплощающих ту или иную человеческую жизнь; поэтому подобные мифологические образы трактуются еще и как «богини судьбы». Таким образом, полотно, как и традиционный рукотворный текстиль в целом, символизировало жизненный путь человека.

В славянской культуре сакрализована не только технология изготовления текстиля, но и его орнаментация. В условиях старой русской деревни украшение тканей являлось для крестьянки наиболее доступным видом декоративно-прикладного искусства, возможностью проявить свои творческие способности и мастерство [8, с. 3]. Полотенце, пояс и рубаха несут на себе объемный сложно-смысловой орнаментальный пласт. Так, например, полотенце - самый распространенный из орнаментированных предметов традиционной культуры; его декоративный ряд может включать вышивку, узорное тканье, кружево, аппликацию: как по отдельности, так и в разнообразных сочетаниях. Не менее выразителен декор праздничных мужских и женских рубах и поясов.

Все три предмета можно выделить в особую группу по тому исключительному значению, которое они имеют в качестве артефактов обрядности, имеющей дохристианское происхождение, прежде всего семейной - родильно-крестильной, свадебной и погребальной. В родильных ритуалах роженица снимала пояс, чтобы облегчить роды; муж развязывал воротник рубахи и пояс; расстилался красный пояс, через который роженица должна была переступить [9, с. 18]. Устойчивой традицией, дожившей до XX века, являлся ритуал принятия новорожденного на домотканое полотенце. Не менее распространенным был обычай заворачивать младенца в рубаху отца, которую с него снимали тут же, объясняя это тем, что будто бы новорожденного больше не во что завернуть; на самом деле обычай преследовал цель обеспечить ребенку отцовскую привязанность с первых минут его жизни. После рождения ребенка опоясывали тонкой ниткой - прообразом настоящего пояса, который имел значение оберега: в этом отношении он приравнивался к крестику и заменял его до обряда крещения, который мог быть проведен несколько недель, а то и месяцев, спустя. В дальнейшей жизни человека пояс сопровождал его как обязательный элемент одежды, который допустимо было снимать только дома - в личном пространстве, «микромире», защищенном от проникновения злых сил.

В свадебной обрядности особенно велико значение рубахи - центрального элемента всего наряда, как мужского, так и женского. Рубаха - самый яркий, богато украшенный компонент русского костюма, объединяющий в себе функции нательной и верхней одежды. Несмотря на кажущуюся простоту, она представляет собой многосоставную, многослойную текстильную конструкцию, в которой каждому элементу отведена своя особая роль. Так, например, основная часть рубахи - «стан», или «становина», в большей мере отвечала положению нательной одежды, выполняя преимущественно утилитарную роль: не видная под сарафаном, она кроилась из более простой ткани и плотно прилегала к телу, поэтому быстрее снашивалась, зато легко могла быть заменена. В мужских рубахах элементом, прилегавшим к телу, предупреждавшим быстрое их снашивание, являлась «подоплека» - плечевая вставка из простой ткани, подшитая изнутри к лицевой орнаментированной основе.

Верхняя часть женской рубахи, носимой в комплекте с сарафаном, образовывала видимую часть костюма, называвшуюся «рукава», или «чехлик». Как нарядный, декорированный элемент, «рукава» кроились из более качественной ткани и несли на себе верхний, основной орнаментальный ряд всего костюма, поскольку декор - преимущественно вышивка, располагался на открытых, наиболее заметных его частях, вороте и оплечьях - «поликах». Декор мог располагаться и вдоль, и поперек плеча; особенно интенсивно декорировались плечевые швы [10, с. 97]. Можно отметить, что швы - стыки, соединения частей, считались местами, наиболее непрочными, уязвимыми для проникновения враждебных человеку сил, что и обусловило их усиленное декорирование; подобные представления существовали не только в отношении одежды, но и жилища. 
Свадьба как центральный момент в жизни человека, была насыщена обереговой магией, в которой одежде отводилась важнейшая роль. В ритуальных целях, как правило, использовались ее типы и варианты, наиболее архаичные по своему происхождению. Поэтому свадебная одежда выделяется не только цветовой гаммой, с преобладанием сочетаний белого, красного и черного (иногда заменяемого синим) цветов, но и орнаментикой, которая на свадебных рубахах особенно плотна и обильна. В качестве примера можно привести свадебные рубахи старообрядцев Рудного Алтая, в культуре которых дохристианская архаика, по ряду причин, прослеживается особенно отчетливо.

Значимым компонентом свадебных обычаев и обрядов также являлось полотенце: и как предмет приданого невесты, и как ее подарок родным жениха. Полотенцем связывали руки участники обряда «рукобитья», завершавшего и скреплявшего сватовство; полотенцем обертывали икону во время обряда благословления родителями молодых; в некоторых локальных традициях полотенцами опоясывали жениха и невесту; хлебом-солью, положенными на полотенце, родители встречали молодых по приезде их от венца в дом жениха. Полотенцем во время свадьбы связывали молодых, символически прикрепляя их друг к другу [11, с. 107]. Полотенцами, крест-накрест или через плечо, перевязывали свадебных дружек; при этом употребляли не только полотенца, но и особым образом завязанные пояса, что говорит о семантической близости этих двух предметов как элементов ритуала. Для украшения свадебного поезда использовали специальные нарядные вожжи, которые ткали в той же технике, что и пояса.

В погребальной обрядности рубаха и пояс присутствуют в качестве главных элементов «смертной» одежды, загодя заготавливаемой пожилыми людьми, с соблюдением всех обрядов, присущих той или иной локальной культуре. Стоит отметить, что во многих традициях для облачения умерших использовали свадебную одежду, особенно, если умирала незамужняя девушка. Полотенца, чаще всего без вышивки, или просто длинные полосы неорнаментированного, и даже неотбеленного льна - так называемой «новины», использовались при изготовлении носилок для транспортировки гроба на кладбище. На этих же полотенцах, или полосах холста, гроб опускался в могилу. В других случаях вместо полотенец употреблялись тканые пояса или вожжи, что является еще одним фактом взаимозаменяемости, а, следовательно, - семиотической близости пояса и полотенца. Полотенечное полотно после погребения разрывалось на фрагменты и раздавалось участникам похоронного действия, что символизировало окончание жизненного пути умершего. До наших дней дошел обычай привязывания полотенца, или фрагмента полотна, на котором спускали в гроб, на надмогильный крест [11, с. 113].

Примеры использования всех трех указанных предметов в разного рода ритуалах можно продолжать и далее. У старообрядцев-«поляков» Алтая отмечен обычай сложной крестообразной обвязки, состоящей из нескольких поясов, которую надевали молодожены - участники масленичных катаний, что соответствовало такому компоненту обрядности Масленицы, как чествование молодых пар, поженившихся в истекший мясоед [12, с. 77-78]. Вместе с тем, присутствие этих артефактов в календарно-праздничной обрядности просматривается в значительно меньшей степени, чем в семейной, поскольку, если семейные ритуалы связаны преимущественно с домом, то праздничные - в основном с улицей; предметы же, о которых идет речь, являлись объектами заботы и сбережения, что не всегда совместимо с уличными гуляниями, процессиями и забавами. В домовом пространстве календарного праздника выступает на первый план роль полотенца-«стеновика», или стенового плата, объемный декор которого исключает его использование в утилитарных целях, как обычного "рукотерта». Такие полотенца развешивали на стенах и в простенках избы; в конце XIX - начале XX века в интерьере жилища полотенце располагалось также на зеркалах и портретах, развешанных на стенах, являясь, таким образом, центральным, доминирующим элементом праздничного «наряда» избы [11, с. 48].

Важным аргументом в пользу значения указанных предметов как артефактов ритуальной культуры является то обстоятельство, что все они, сформировавшись в дохристианской древности, были переосмыслены в качестве неотъемлемых компонентов христианского культа. 
Если рубаха и пояс стали обязательными элементами моленной одежды, что хорошо просматривается в специфических обычаях и требованиях старообрядцев, то полотенце прочно закрепилось как важный элемент оформления домашнего алтаря, обрамляющий иконы на божницах, располагавшихся в красном углу. (Как известно, красный угол является наиболее значимой в семиотическом отношении частью дома, в которой проходили важнейшие ритуалы семейной обрядности). Данное обстоятельство вызвало к жизни разновидность специальных божничных полотенец, изготовляемых по традиционной, веками отработанной технологии, только с измененным декором, в котором место древних ромбических символов и мотивов «древа жизни» заняли вышитые кресты, храмы и слова молитв.

Представляется очевидным, что все три вещи - полотенце, пояс и рубаха, являются центральными атрибутами ритуалов жизненного цикла и, соответственно, могут и должны интерпретироваться в качестве таковых в пространстве музейной экспозиции. Устойчивое присутствие рубахи, полотенца и пояса в семейной обрядности, безусловно, отражает представления об этих, важнейших с точки зрения человека традиционной культуры, вехах жизненного пути. Таким образом, очевидно, что именно мировоззренческие представления сформировали и сами соответствующие ритуалы, и образы их атрибутов, а также обусловили их значение и роль.

В содержательном аспекте, характеризующем памятники материальной культуры, можно выделить и другие мировоззренческие смыслы. Как справедливо отмечено исследователями, в русском костюме отражены эстетические предпочтения народа, отражающие его представления о красоте [8, с. 3]. Кроме того, с одеждой связаны представления о норме, социализации, морали и нравственности, а также самосознание и этническая самоидентификация, поскольку одежда является важнейшим маркером принадлежности к тому или иному народу, этнографической или этноконфессиональной группе.

Не обладая научными знаниями о природе и человеке, наши предки, в рамках своих этнокультурных и религиозных обществ, сумели выстроить простую и понятную систему мироздания, объясняющую им явления окружающего мира. Поэтому за каждым ритуалом стоит та или иная трактовка мироустройства, основанная на связях человека с силами природы, с которой он сосуществует и по мере возможности преобразует, формируя свою среду обитания; продуктом этой творческой работы является культура. В ритуалах также отражены представления человека и о тех частях мироздания, которые ему недоступны, но, по его убеждению, самым непосредственным образом влияют на его жизнь - о мире мертвых и мире богов, с которыми ему поэтому чрезвычайно важно выстроить правильные отношения. Мифологизированная система миропонимания идеальна, невещественна, поскольку является продуктом сознания; материальные же атрибуты ритуала являются лишь зримым отражением этих идей.

Все вышесказанное подтверждает заявленный нами тезис о том, что материальный, рукотворный мир, созданный усилиями человека, является отражением его мировоззренческих установок, а не наоборот. Именно поэтому каждая вещь является отражением создавшей ее культуры, хотя в разных памятниках это свойство проявляется не в равной мере. Особую ценность в данном отношении представляют собой артефакты, в которых признаки этнокультуры пересекаются с сакральными функциями того или иного религиозного культа, отправляемого посредством ритуалов.

Для музейного специалиста-экспозиционера вещественный памятник является ключом, позволяющим не только раскрыть культурную идентичность людей отдаленных эпох, но и актуализировать эти смыслы, связать их с идеологическим наполнением современного общества, выделить в нем элементы, находящие отголоски в далеком прошлом. Все это, вместе взятое, позволяет ему восстановить связь времен: приблизить к нам наших предков, делая более понятными их жизненные устремления, научить музейного зрителя видеть в их представлениях, вместо проявлений отсталости и невежества, умение сосуществовать с природой, проходить свой жизненный путь в гармонии со своим кормящим ландшафтом, социумом и, что еще более важно, в мире с самими собой. В этом, на наш взгляд, состоит главная миссия современного музея. 


\title{
Список литературы
}

1. Мастеница, Е.Н. Нематериальное наследие как объект музеефикации: теоретикометодологические основания // Культура в евразийском пространстве: традиции и новации. - 2017. - № 1. - C. 79-85.

2. Курьянова, Т. С. Музей и нематериальное культурное наследие // Вестник Томского государственного университета. - 2012. - № 361. - С. 55-57.

3. Чусова, Н. А. Из опыта демонстрации нематериального наследия в музее-заповеднике «Кижи» // Актуальные проблемы развития музеев-заповедников : тез. докл. Всерос. науч-практ. конф. (Петрозаводск-Кижи, июнь 2006 г.). - Петрозаводск: [б. и.], 2006. - С. 204-209. - URL: http://kizhi.karelia.ru/library/aktual/571.html (дата обращения: 02.06.2021).

4. Окладникова, Е. А. Семиозис музейного предмета // Радловские чтения - 2006: тез. докл. Санкт-Петербург : Музей антропологии и этнографии им. Петра Великого (Кунсткамера) Рос. академии наук, 2006. - C. 73-91. - URL: https://www.kunstkamera.ru/files/lib/5-88431-126-6/5-88431-126-6_19.pdf (дата обращения: 04.06.2021).

5. Лебедева, А. А. Значение пояса и полотенца в русских семейно-бытовых обычаях и обрядах XIX - ХХ вв. // Русские: семейный и общественный быт / отв. ред. М. М. Громыко, Т. А. Листова. - Москва : Наука, 1989. - С. 229-248.

6. Рыбаков, Б. А. Язычество древних славян. - Москва : Индрик, 1994. -608 с.

7. Колосов, Д.А. Образ Великой Матери в мировой культуре (единично-бинарно-троичночетверичная проекция)// Известия Тульского университета. Гуманитарные науки. - 2011. - № 2. C. $128-140$.

8. Работнова, И. П. Русская народная одежда. - Москва : Лёгкая индустрия, 1964. - 56 с.

9. Ткань - ритуал - человек. Традиции ткачества славян Восточной Европы / [авт.-сост. О. В. Лысенко, С. В. Комарова]. - Санкт-Петербург : [б. и.], 1992. - 48 с.

10. Шмелёва, М. Н. Украшения русской крестьянской одежды / М. Н. Шмелёва, Л. В. Тазихина // Русские. Историко-этнографический атлас / гл. ред. С. П. Толстов. - Москва : Наука, 1970. - С. 89-129.

11. Абрамова, О. А. Традиционная одежда «поляков»-староверов села Сибирячиха Солонешенского района Алтайского края // Этнография Алтая и сопредельных территорий : матер. междунар. науч.практ. конф. (Барнаул, 23-26 сент. 2003 г.). - Барнаул : Изд-во Барнаульского гос. пед. ун-та, 2003. C. $74-79$.

12. Грибанова, Н. С. Полотенце в культуре русского населения Алтая в конце XIX - начале XXI века. - Барнаул : Изд-во Алт. гос. пед. академии, 2013. - 256 с.

Irina $\boldsymbol{V}$. Kupriianova, Dr. of Historical Sciences, Associate Professor Altai State Institute of Culture (Barnaul, Russia) irinak-63@mail.ru

\section{AN ETHNOGRAPHIC MONUMENT AS AN INTANGIBLE HERITAGE BRINGER}

\begin{abstract}
The article takes an attempt to argue primariness of intangible heritage toward tangible one exhibited in ethnographic collections of museums using the example of semantic analysis of key (on the author's view) monuments of East-Slavic ethnic culture. The researcher shows hierarchic relation between both components of culture in which museum monuments are materialized ideas that reflected traditional views on world structure, ethic and aesthetic notions and preferences. The possibilities of revealing the features of the ethnic worldview through a thing are considered.

Key words: Russians, intangible heritage, tangible heritage, traditional culture, ethnic culture, worldview, East Slavic pre-Christian beliefs, sacredness, traditional textiles.
\end{abstract}

